\section{Case Reports in Ophthalmology}

Case Rep Ophthalmol 2020;11:528-533

DOI: $10.1159 / 000508327$

Published online: October 13, 2020 (c) 2020 The Author(s)

Published by S. Karger AG, Basel

www.karger.com/cop

This article is licensed under the Creative Commons Attribution-NonCommercial 4.0 International License (CC BY-NC) (http://www.karger.com/Services/OpenAccessLicense). Usage and distribution for commercial purposes requires written permission.

\title{
Bilateral Macular Hole Related to Tamoxifen Low-Dose Toxicity
}

\author{
Nuria Torrell Belzach ${ }^{a}$ José Ignacio Vela Segarra ${ }^{a-c}$ \\ Jaume Crespí Vilimelis ${ }^{a, b} \quad$ Mohammed Alhayek $^{a}$ \\ aDepartment of Ophthalmology, Hospital de la Santa Creu i Sant Pau, Barcelona, Spain; \\ bInstitut Condal d'Oftalmologia, Barcelona, Spain; 'Autonomous University of Barcelona, \\ Barcelona, Spain
}

\section{Keywords}

Macular hole $\cdot$ Vitrectomy $\cdot$ Tamoxifen $\cdot$ Retinal toxicity

\begin{abstract}
Bilateral macular hole is a rare secondary effect of tamoxifen, a condition which is probably underdiagnosed. We describe the case of a 63-year-old woman who had received low-dose treatment with tamoxifen for 10 years. She presented with a best-corrected visual acuity of $20 / 40$ in both eyes and bilateral macular hole with posterior hyaloid attachment. No reflective deposits were observed. A 23-gauge pars plana vitrectomy with internal limiting membrane peeling and gas tamponade was performed in the right eye with no anatomical or functional improvement. The most accepted mechanism of macular hole related to tamoxifen is Müller cell toxicity with retinal tissue loss. Therefore, it seems that the standard procedure used in idiopathic macular hole is not the optimal choice, due to a different pathogenic mechanism.

\section{Introduction}

Tamoxifen is a non-steroidal selective estrogen receptor modulator used as adjuvant endocrine therapy in estrogen receptor-positive breast cancer. This drug can induce some ocular complications such as crystalline maculopathy, macular edema, retinal vein occlusions,

\section{KARGER}

José Ignacio Vela Segarra

Department of Ophthalmology, Hospital de la Santa Creu i Sant Pau

Sant Antoni Maria Claret, 167

ES-08025 Barcelona (Spain)

ivela@santpau.cat 
bilateral optic neuritis, and corneal opacities [1]. Recently, some studies have demonstrated that low-dose treatment can be extended up to 10 years, as tamoxifen can reduce relapse of cancer in patients at high risk of recurrence [2]. A relationship between the development of macular hole $(\mathrm{MH})$ and low-dose tamoxifen (usually considered a cumulative dose $<100 \mathrm{~g}$ ) has been recently described [3-8], but the management remains controversial.

\section{Case Report}

A 63-year-old woman with a history of breast cancer presented with mild, progressive, bilateral visual loss for years with no prior ocular history. The patient had received $20 \mathrm{mg}$ of tamoxifen daily for approximately 10 years (cumulative dose around $73 \mathrm{~g}$ ). She began with this adjuvant therapy following a mastectomy, which had been done rapidly after diagnosis at age 41 . Therefore, she had not received tamoxifen for 12 years at presentation. Her best corrected visual acuity was 20/40 in both eyes (BE). Slit lamp examination of the anterior segment was unremarkable. Dilated fundus examination showed an irregular foveal light reflex with pseudohole appearance and no evidence of reflective deposits in the inner layers, which excluded crystalline maculopathy (Fig. 1a, b). Spectral-domain optical coherence tomography (SD-OCT) showed a bilateral MH with a thin overlying roof of inner retinal remnant. Some small cystic spaces on the edges of the hole and attachment of the posterior hyaloid (PH) were also observed with no evidence of thickening or macular edema (Fig. 1c, d). Fluorescein angiography (FA) showed a progressive and diffuse hyperfluorescence in the fovea of BE with no late phase leakage (Fig. 2). FA allows to differentiate retinal changes related to tamoxifen retinopathy, which may be similar on SD-OCT to the ones found in macular telangiectasia type 2 (MacTel2) [9]. Nevertheless, a late leakage of telangiectatic macular capillaries is observed in FA of eyes with MacTel2 [10]. Thus, the diagnosis of bilateral MH related to tamoxifen toxicity was made.

A 23-gauge pars plana vitrectomy (PPV) with internal limiting membrane (ILM) peeling and sulfur hexafluoride $\left(\mathrm{SF}_{6}\right) 24 \%$ gas tamponade was performed in the right eye (RE). The patient rested in prone position for 6 days. The MH remained opened with elevated edges after surgery (Fig. 3). A second 23-gauge PPV was proposed, but the patient rejected it. The patient has been followed for 4 years with no changes in visual acuity (best corrected visual acuity of 20/40 in BE) or SD-OCT images.

\section{Discussion}

The incidence of MH due to tamoxifen toxicity is expected to increase as the tendency is to extend low-dosage tamoxifen treatment. Furthermore, the increasing use of SD-OCT will probably raise the number of cases. Surgical outcome of secondary MH related to tamoxifen toxicity remains unclear. It is worth noticing that in our case BE showed still attached PH, which suggests a different pathomechanism from idiopathic $\mathrm{MH}$, where anteroposterior and tangential traction forces after posterior vitreous detachment are thought to be the main cause of this condition. Therefore, it seems that in this type of secondary MH the standard procedure used in idiopathic MH (i.e., PPV with ILM peeling and gas tamponade) would not be effective, as it seems more related to degenerative mechanisms that lead to tissue loss in the retina. The most accepted mechanism of MH related to tamoxifen is that toxic damage 


\section{Case Reports in Ophthalmology}

Case Rep Ophthalmol 2020;11:528-533

DOI: $10.1159 / 000508327$

(c) 2020 The Author(s). Published by S. Karger AG, Basel www.karger.com/cop

Torrell Belzach et al: Macular Hole Related to Tamoxifen

culminates in axonal degeneration leading to Müller cell impairment. It may cause intraretinal foveolar cysts, which in turn would predispose MH formation [11].

Due to the increasing use of SD-OCT and the new trend to extent low-dosage treatment, foveolar cavitations with outer retinal defect and MH related to tamoxifen have been described [4, 5, 7, 8]. In 2005, Gualino et al. [3] first described this complication, and additionally in the same year, Cronin et al. [6] reported a retrospective analysis of 300 consecutive cases of $\mathrm{MH}$ and concluded that there was a statistically increased incidence of $\mathrm{MH}$ in women treated with tamoxifen.

Concerning the crystalline deposits status in low-dose tamoxifen toxicity, crystalline retinopathy has classically been thought to be the hallmark of tamoxifen toxicity. This association was based on patients treated with high-dose tamoxifen [12]. Superficial crystals have also been observed in patients with early cavitary spaces. Furthermore, more advanced cavitations without visible crystals have been demonstrated in patients who received low-dose tamoxifen $[5,7]$. Thus, crystalline maculopathy could represent an earlier finding in tamoxifen toxicity with initial Müller cell damage, while foveal cavitations could correspond to a later stage of atrophy where the crystals have degenerated. Doshi et al. [7] also suggested this possibility after reporting the case of a woman who had received a cumulative dose of tamoxifen of 18.25 mg with evidence of ILM draping with prominent crystals and a small cavitary space in the central fovea on the RE. On the contrary, the left eye of the same patient did not show any visible crystals, although a nearly full thickness cavitation was demonstrated [7]. Therefore, the absence of crystals in the posterior pole might be a common manifestation of late stages of low-dose tamoxifen maculopathy, although more longitudinal follow-up studies are needed to confirm this hypothesis.

Regarding the treatment, Chung et al. [5] reported MH closure and visual improvement in two patients with MH related to systemic antiestrogen agents through surgery with solely 23gauge PPV and ILM peeling, although crystalline deposits were not found and there was no description about PH membrane status. Even though, Bernstein and DellaCroce [13] also presented the case of a woman who had received tamoxifen with bilateral MH coexisting with crystalline maculopathy who had a previous failed surgery on her RE elsewhere, which was not detailed. A new surgery on her RE with perfluoropropane $\left(\mathrm{C}_{3} \mathrm{~F}_{8}\right)$ tamponade successfully closed the $\mathrm{MH}$. Nevertheless, the same surgery was performed on her left eye with no improvement and persistent MH on following examinations [13].

\section{Conclusion}

We suggest that observation of MH related to low-dose tamoxifen is a feasible option at this time due to poor functional results after vitrectomy and ILM peeling found in our case and the previous case described by Bernstein and DellaCroce [13]. Nevertheless, more studies are needed in order to understand the evolution of tamoxifen associated with $\mathrm{MH}$, possible precursor lesions, and their optimal management.

Patients with reduced visual acuities may not be aware of their visual deficits initially, as in our case. Macular cavitations and holes due to tamoxifen may occur in the absence of subjective visual complaints. Hence, we strongly recommend - whenever possible - a complete ophthalmologic exam including SD-OCT in those patients under treatment with tamoxifen, regardless of subjective absence of visual impairment.

Finally, if any macular cavitations are observed, a FA should be performed in order to exclude MacTel2. Thus, if any sign of retinal toxicity is detected promptly in those patients 


\section{Case Reports in Ophthalmology}

Case Rep Ophthalmol 2020;11:528-533

(c) 2020 The Author(s). Published by S. Karger AG, Basel www.karger.com/cop

Torrell Belzach et al: Macular Hole Related to Tamoxifen

under treatment with tamoxifen, progressive visual acuity deterioration could be avoided by considering tamoxifen discontinuation in agreement with the oncologist after considering the risk-benefit profile in each individualized case.

\section{Statement of Ethics}

Verbal and written informed consent was obtained from the patient for publication of this case report and all accompanying images.

\section{Conflict of Interest Statement}

The authors have no conflict of interest to declare.

\section{Funding Sources}

Not applicable.

\section{Author Contributions}

All authors collected and interpreted the patient's clinical findings. N.T.B. and J.I.V.S. contributed to the writing and editing of the manuscript. N.T.B. reviewed the literature. All authors read and approved the final version of the manuscript.

\section{References}

1 Ugurlu S, Karagoz A, Altin Ekin M. Ocular findings in breast cancer patients using tamoxifen. Cutan Ocul Toxicol. 2015 Mar;34(1):16-20.

2 Rossi L, McCartney A, De Santo I, Risi E, Moretti E, Malorni L, et al. The optimal duration of adjuvant endocrine therapy in early luminal breast cancer: A concise review. Cancer Treat Rev. 2019 Mar;74:29-34.

3 Gualino V, Cohen SY, Delyfer MN, Sahel JA, Gaudric A. Optical coherence tomography findings in tamoxifen retinopathy. Am J Ophthalmol. 2005 Oct;140(4):757-8.

$4 \mathrm{Hu}$ Y, Liu N, Chen Y. The optical imaging and clinical features of tamoxifen associated macular hole: A case report and review of the literatures. Photodiagn Photodyn Ther. 2017 Mar;17:35-8.

5 Chung SE, Kim SW, Chung HW, Kang SW. Estrogen antagonist and development of macular hole. Korean J Ophthalmol. 2010 Oct;24(5):306-9.

6 Cronin BG, Lekich CK, Bourke RD. Tamoxifen therapy conveys increased risk of develo ping a macular hole. Int Ophthalmol. 2005 Jun;26(3):101-5.

7 Doshi RR, Fortun JA, Kim BT, Dubovy SR, Rosenfeld PI. Pseudocystic foveal cavitation in tamoxifen retinopathy. Am J Ophthalmol. 2014 Jun;157(6):1291-1298.e3.

8 Caramoy A, Scholz P, Fauser S, Kirchhof B. Imaging tamoxifen retinopathy using spectral-domain optical coherence tomography. GMS Ophthalmol Cases. 2011 Dec;1:Doc07.

9 Lee S, Kim HA, Yoon YH. OCT angiography findings of tamoxifen retinopathy: similarity with macular telangiectasia type 2. Ophthalmol Retina. 2019 Aug;3(8):681-9.

10 Behrens A, Sallam A, Pemberton J, Uwaydat S. Tamoxifen use in a patient with idiopathic macular telangiectasia type 2. Case Rep Ophthalmol. 2018 Jan;9(1):54-60.

11 Bringmann A, Pannicke T, Grosche J, Francke M, Wiedemann P, Skatchkov SN, et al. Müller cells in the healthy and diseased retina. Prog Retin Eye Res. 2006 Jul;25(4):397-424.

12 Kovach JL, Isildak H, Sarraf D. Crystalline retinopathy: unifying pathogenic pathways of disease. Surv Ophthalmol. 2019 Jan - Feb;64(1):1-29.

13 Bernstein PS, DellaCroce JT. Diagnostic \& therapeutic challenges. Tamoxifen toxicity. Retina. 2007 Sep;27(7):982-8. 


\section{Case Reports in Ophthalmology}

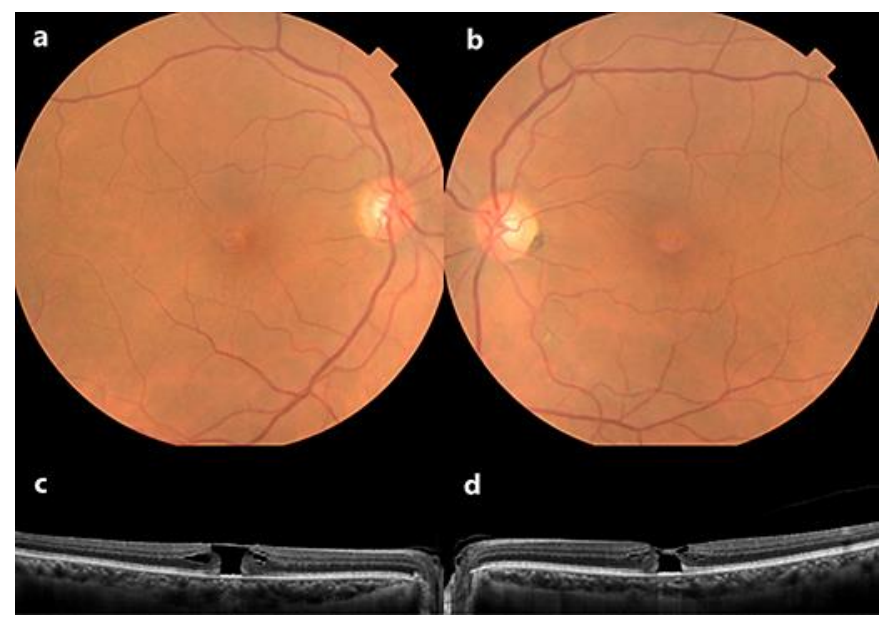

Fig. 1. a Fundus image of the right eye. b Fundus image of the left eye. An irregular foveal light reflex with a pseudohole appearance is shown in both eyes. c Optical coherence tomography of the right eye before surgery showing full thickness macular hole with some cystic spaces on the edges. The posterior hyaloid is attached and draping of the internal limiting membrane is also observed. $\mathbf{d}$ Optical coherence tomography of the left eye showing a foveal cavitation with defect on the outer retinal layers and focal disruption of the photoreceptor layer with sharp edges, which present some cystic spaces. Internal limiting membrane and inner retina bridge are present, and posterior hyaloid is attached.

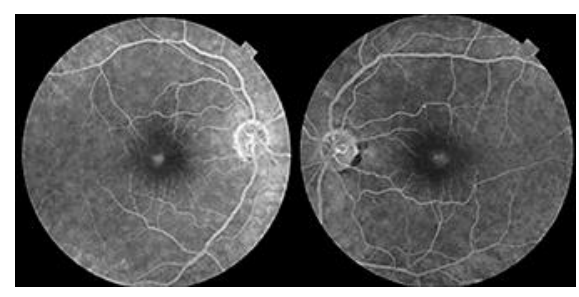

Fig. 2. Fluorescein angiography showing a progressive and diffuse hyperfluorescence in the fovea of both eyes with no late phase leakage. 
Case Reports in Ophthalmology (c) 2020 The Author(s). Published by S. Karger AG, Basel www.karger.com/cop

Torrell Belzach et al.: Macular Hole Related to Tamoxifen

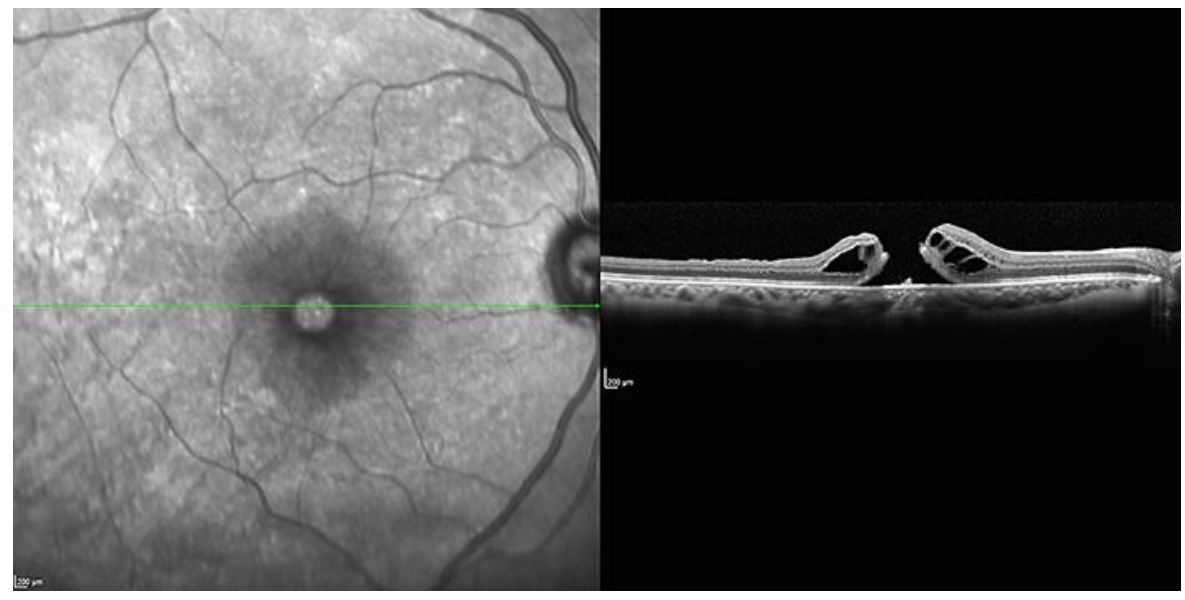

Fig. 3. Optical coherence tomography of the right eye showing full thickness macula hole with thickened retinal edges 3 weeks after surgery. 